\title{
Silver nanoparticles-chitosan composites activity against resistant bacteria: tolerance and biofilm inhibition
}

\author{
Eduarda Melquiades Pirette dos Santos • Carla Castelo Branco Martins • João Victor de Oliveira Santos • \\ Wagner Roberto Cirilo da Silva $\cdot$ Sidicleia Bezerra Costa Silva $\cdot$ Miguel Angel Pelagio-Flores • \\ André Galembeck · Isabella Macário Ferro Cavalcanti
}

Received: 25 May 2020 / Accepted: 16 August 2021 / Published online: 24 August 2021

(C) The Author(s), under exclusive licence to Springer Nature B.V. 2021

\begin{abstract}
This study aimed to evaluate the effectiveness of silver nanoparticles-chitosan composites (AgNPs) with different morphologies and particle size distributions against resistant bacteria and biofilm formation. Four different samples were prepared by a two-step procedure using sodium borohydride and ascorbic acid as reducing agents and characterized by UV-Vis absorption spectra, scanning transmission electron microscopy. The minimum inhibitory concentration (MIC) and minimum bactericidal concentration (MBC) of the AgNPs were determined according to the Clinical and Laboratory Standards Institute (CLSI) against clinical isolates multidrugresistant and strains of the American Type Culture Collection (ATCC). An assay was performed to
\end{abstract}

Supplementary Information The online version contains supplementary material available at https://doi. org/10.1007/s11051-021-05314-1.

E. M. P. dos Santos - C. C. B. Martins .

J. V. de Oliveira Santos · W. R. C. da Silva .

I. M. F. Cavalcanti $(\square)$

Laboratory of Immunopathology Keizo Asami (LIKA),

Federal University of Pernambuco (UFPE), Av. Prof.

Moraes Rego, 1235, Cidade Universitária, Recife,

Pernambuco CEP: 50670-901, Brazil

e-mail: isabella.cavalcanti@ufpe.br

S. B. C. Silva · M. A. Pelagio-Flores · A. Galembeck Department of Fundamental Chemistry, Federal University of Pernambuco (UFPE), Av. Jorn.

Aníbal Fernandes, s/n, Cidade Universitária, Recife,

Pernambuco CEP: 50740-560, Brazil determine the MICs during 20 successive bacteria exposures to AgNPs to investigate whether AgNPs induce tolerance in bacteria. The antibiofilm activities of AgNPs were also evaluated by determining the minimum biofilm inhibitory concentration (MBIC). The spherical AgNPs present diameters ranging from 9.3 to $62.4 \mathrm{~nm}$, and some samples also have rod-, oval-, and triangle-shaped nanoparticles. The MIC and $\mathrm{MBC}$ values ranged from 0.8 to $25 \mu \mathrm{g} / \mathrm{mL}$ and 3.1 to $50 \mu \mathrm{g} / \mathrm{mL}$, respectively. Smaller and spherical AgNPs exhibited the highest activity, but all the AgNPs developed in this study exhibit bactericidal activity. There was no significant MIC increase after 20 passages to the AgNPs. Regarding the antibiofilm activity, MBICs ranged from 12.5 to $50 \mu \mathrm{g} / \mathrm{mL}$. Again, smaller and spherical nanoparticles presented the best results with phenotypic inhibition of production of slime or exopolysaccharide (EPS) matrix. Thus, it was concluded that AgNPs have a promising potential against resistant bacteria and bacteria that grow on biofilms without inducing tolerance.

Keywords Silver nanoparticles-chitosan composites $\cdot$ Resistance $\cdot$ Biofilm $\cdot$ Tolerance $\cdot$ Health effects

\section{Introduction}

Bacterial infections remain one of the leading causes of death for millions of people worldwide, and, in 
2019, antimicrobial resistance appeared in the World Health Organization (WHO) list "Ten threats to global health" (WHO 2019). When an infection is acquired in a clinical environment, with manifestations during hospitalization or after discharge, it is classified as a nosocomial or healthcare-associated infection (HAI). The transmission of resistant bacteria among hospitalized patients is numerous and frequently aggravates their health condition (Brazil 1997; WHO 2002; Jenkins 2017).

According to the Centers for Disease Control and Prevention, in the USA, nearly 3 million people are infected with antibiotic-resistant bacteria and fungi every year, and 35,900 die as a consequence (CDC 2019). The concerns caused by this issue worldwide led WHO to launch the Global Action Plan on Antimicrobial Resistance in 2015, considering that "It reflects a global consensus that antimicrobial resistance poses a profound threat to human health" (WHO 2015).

The insurgence of resistant bacteria occurs due to a number of factors such as over-prescribing of antibiotics, poor infection control in clinics, and poor hygiene and sanitation practices. The outcome is an increase in the number of antibiotic-resistant bacteria and the emergence of resistance to multiple drugs and extremely drug-resistant bacteria (Khameneh et al. 2016; Marston et al. 2016).

Biofilm is the predominant life-mode of most bacterial species and a virulence factor that increases bacterial resistance since they act as barriers for the antibiotics' action and can also promote the development of resistance due to cell contact and DNA acquisition from the bacterial communities and environment. Biofilms are also responsible for most chronic and recurrent human bacterial infections. They help the microorganisms survive in hostile environments with physiology and behavior significantly different from their free-living (planktonic) counterparts. Bacteria that grow on biofilms are highly resistant to antibiotic therapy due to the exopolysaccharide (EPS) matrix providing anchorage and making them less susceptible to therapeutic agents (Venkatesan et al. 2015; Flemming et al. 2016; Jamal et al. 2018).

Even though new generations of antimicrobials have been developed in the last few decades, none has shown to be fully effective against multidrug-resistant bacteria and bacteria that grow on biofilms because it is a double challenge for the choice of treatment
(Jamal et al. 2018; Hauser et al. 2016). Hence, other strategies are mandatory, and pharmaceutical nanotechnology is promising to generate new therapeutic products for biomedical applications. Nanotechnology has already opened new doors to researchers dealing with infections caused by resistant bacteria and bacteria that grow on biofilms (Yang et al. 2012; Gurunathan et al. 2014; Natan and Banin 2017). The antimicrobial effectiveness activity of silver nanoparticles (AgNPs) against bacteria, fungi and, viruses have been extensively documented in the literature in the last two decades (Chaloupka et al. 2010; Ssekatawa et al. 2020). They are currently considered the most promising candidate for developing a new generation of antibiotics since the mechanisms of action are, in principle, difficult to overcome by bacteria. In essence, the AgNPs bactericidal activity is related to their capacity to adhere to the cell walls (Zheng et al. 2018). Several mechanisms triggered by the release of ionic silver $\left(\mathrm{Ag}^{+}\right)$can kill bacteria, and even though some take place in the inner part of the cells, this is not a requirement that must be fulfilled. Hence, AgNPs can be less susceptible to the development of bacterial resistance (Wang et al. 2017).

The antimicrobial action of AgNPs relies on silver oxidation to $\mathrm{Ag}^{+}$overwritten and its release to the bacteria (Noronha et al. 2017). Consequently, factors such as particle size and morphology, capping agent, aggregation, and synergistic effects with other molecules or nanostructures are important. When spherical nanoparticles are considered, a smaller size tends to result in a higher efficiency since the higher surface area is more prone to dissolution than the larger ones. For the same reason, aggregated nanoparticles have lower activity than isolated nanoparticles (Le Ouay and Stellacci 2015a; Pal et al. 2007; Zhang et al. 2016). These features can be tailored to prepare AgNP colloids if strict control over the synthesis can be attained.

Our research group has demonstrated AgNPsbased formulations' effectiveness as a caries arrestment agent in clinical trials (Dos Santos et al. 2014), and the formulations also have low toxicity (Targino et al. 2014; Freire et al. 2015). The present study investigated the antibacterial and antibiofilm activities and the tolerance of AgNPs with different sizes and morphologies against pathogenic bacteria, including resistant clinical isolates. 
Finally, people at the most significant risk of suffering from infections caused by resistant bacteria already had a decreased immunologic system. H1N1 influenza, in 2009, resulted in almost 300,000 deceases worldwide, and it was estimated that $29 \%$ to $55 \%$ of these resulted from subsequent bacterial action (Morris et al. 2017). Probably, a similar picture will result from the COVID-19 pandemic. It is urgent to find alternatives.

\section{Material and methods}

\section{Material}

The culture media used in this study were obtained from Himedia and Kasvi, and all solvents were purchased from Merck. Sigma-Aldrich supplied antimicrobial agents. The bacteria were stored at $-80{ }^{\circ} \mathrm{C}$ in brain heart infusion broth (BHIB) containing $20 \%$ glycerol as a cryoprotectant in the Laboratory of Immunopathology Keizo Asami from the Federal University of Pernambuco (LIKA/UFPE).

Silver nitrate $\left(\mathrm{AgNO}_{3}\right)$, sodium borohydride $\left(\mathrm{NaBH}_{4}\right)$, ascorbic acid, glacial acetic acid, and chitosan (75-85\% deacetylation degree) were all supplied by Sigma-Aldrich and used without further purification. Ultrapure sterile water (conductivity $=18.0 \mathrm{M} \Omega$ ) was used in all experiments.

The chitosan average $M_{w}$ is $6.95 \times 10^{5} \mathrm{~g} \cdot \mathrm{mol}^{-1}$ as determined by viscosity measurements (Kasaai et al. 2000), and the deacetylation degree is $79.08 \%$, calculated from FTIR spectroscopy data (Moore and Roberts 1980).

Synthesis of silver nanoparticles-chitosan composites

A two-step procedure was carried out to synthesize the AgNP colloids with different particle sizes and morphologies: (i) the AgNP_1 was prepared by chemical reduction of $\mathrm{Ag}^{+}$ions with $\mathrm{NaBH}_{4}$; (ii) different amounts of the AgNP_1 colloid was used to grow AgNPs with different sizes and morphologies. This methodology was developed following guidelines provided by Bin-Ahmad et al. (Bin-Ahmad et al. 2011) and Stamplecoskie and Scaiano (Stamplecoskie and Scaiano 2011). A detailed description of the method and the characterization was disclosed in a previous publication of our group (Freire et al. 2016).

AgNP_1 was synthesized in an aqueous solution in the presence of low molecular-weight chitosan as a stabilizing agent (Bin-Ahmad et al. 2011; Huang and Yang 2004), as described previously (Dos Santos et al. 2014). An $\mathrm{AgNO}_{3}$ aqueous solution was added to a $1.0 \%$ chitosan solution in acetic acid, followed by adding the $\mathrm{NaBH}_{4}$ solution dropwise under stirring to give a yellow colloid. This step was carried out in an ice bath, and the $\mathrm{Ag}^{+}$to $\mathrm{NaBH}_{4}$ was (1:6).

The other samples were prepared by adding an ascorbic acid aqueous solution to $30.0 \mathrm{~mL}$ of the chitosan solution, followed by the addition of different amounts of AgNP_1: $50 \mu \mathrm{L}$ (AgNP_2), $200 \mu \mathrm{L}$ (AgNP_3), and $300 \mu \mathrm{L}$ (AgNP_4). All samples present nearly the same total silver amount. The resulting particles' final size and morphology will depend on the amount of AgNP_1 added (Stamplecoskie and Scaiano 2011). The resulting AgNP colloids are yellow, orange, red wine, and purple, respectively. The information about the syntheses is summarized in Table 1.

\section{Characterization of AgNPs}

UV-Vis absorption spectra were recorded in an Ocean Optics (HR400CG-UV-NIR) equipment using $1.0 \mathrm{~cm}$ to 1 quartz cuvettes from 300 to $1000 \mathrm{~nm}$ range with water as the reference. All samples' zeta potentials were measured in a Malvern Zetasizer
Table 1 AgNP colloids used in this work and parameters used in the syntheses

\begin{tabular}{lllll}
\hline Sample & $\begin{array}{l}\text { Seed volume } \\
(\mu \mathrm{L})\end{array}$ & $\begin{array}{l}\mathrm{Ag}^{+} \text {solution vol- } \\
\mathrm{ume}(\mu \mathrm{L})\end{array}$ & $\begin{array}{l}\text { Ascorbic acid solution } \\
\text { volume }(\mathrm{mL})\end{array}$ & $\mathrm{Ag}$ total (ppm) \\
\hline AgNP_1 & 4170 & - & - & 100.1 \\
AgNP_2 & 50 & 250 & 0.5 & 115.1 \\
AgNP_3 & 200 & 250 & 0.5 & 112.7 \\
AgNP_4 & 300 & 250 & 0.5 & 109.1 \\
\hline
\end{tabular}


Nano ZS instrument, equipped with a $\mathrm{He}-\mathrm{Ne}$ laser at $633 \mathrm{~nm}$.

The particle morphologies were investigated by scanning transmission electron microscopy (STEM), using a Tescan Mira3 microscope under $25 \mathrm{kV}$ and transmission electron microscopy (TEM), a $200 \mathrm{kV}$ FEI Tecnai20 G2 equipment. The samples were prepared by dilution in deionized water, dropping directly to the grids and allowing them to dry at room temperature for $24 \mathrm{~h}$ before the analyses. STEM images were used to determine the particle size distributions and morphologies of the silver nanoparticles-chitosan composites. A public domain image processing software, ImageJ, was used. At least 300 particles in each sample were counted to generate the statistics results.

\section{Bactericidal activity of AgNPs}

Firstly, the clinical isolates of resistant bacteria and bacteria that grow on biofilms were reactivated in brain heart infusion (BHI) broth from samples preserved in glycerol kept in an ultra-freezer at $-80{ }^{\circ} \mathrm{C}$ at LIKA/UFPE. They were subjected to phenotypic identification of the resistance profile using methods standardized by the Clinical and Laboratory Standards Institute (CLSI 2019), and the biofilm was determined by the crystal violet method (Adukwu et al. 2012). The clinical isolates used in this study were collected from patients in the Clinic Hospital of Pernambuco (HC/UFPE), Brazil: Klebsiella pneumoniae carbapenemase (KPC), polymyxin-resistant Escherichia coli, aminoglycosides-resistant Acinetobacter spp., extended-spectrum beta-lactamase (ESBL)producing enterobacteria (ESBL), and vancomycinresistant Staphylococcus aureus (VRSA). Standard strains of the American Type Culture Collection (ATCC) were also be used, such as Pseudomonas aeruginosa ATCC 27853, Klebsiella pneumoniae ATCC 700603, methicillin-sensitive Staphylococcus aureus (MSSA) ATCC 29213, and methicillin-resistant Staphylococcus aureus (MRSA) ATCC 33591.

The minimum inhibitory concentration (MIC) was determined using the microdilution method according to the CLSI (Freire et al. 2016). Initially, MüellerHinton broth was added to all wells of the microdilution plates. Subsequently, the AgNPs and the silver solution $\left(\mathrm{AgNO}_{3}\right)$ were introduced in concentrations ranging from 0.1 to $50 \mu \mathrm{g} / \mathrm{mL}$. An $\mathrm{AgNO} 3$ solution with the same silver total amount was used as a comparative group with the AgNPs. The bacterial suspensions were adjusted to 0.5 on the McFarland scale, diluted, and deposited in the wells to obtain a 2-5 $10^{5} \mathrm{CFU} / \mathrm{mL}$ final concentration. After that, the plates were incubated at $37 \pm 2{ }^{\circ} \mathrm{C}$ for 22 to $24 \mathrm{~h}$. MIC was determined to be the lowest concentration of the standard drug capable of inhibiting microbial growth through a spectrophotometric at $620 \mathrm{~nm}$. The minimum bactericidal concentration (MBC) was determined after the MIC results. An aliquot of 10 $\mu \mathrm{L}$ was aseptically removed from each well in which no visible bacterial growth was observed and seeded on Müeller-Hinton agar. The plates were incubated at $35{ }^{\circ} \mathrm{C}$ for $24 \mathrm{~h}$. After this incubation, MBC was the lowest concentration, where there was no microbial growth. The experiments were carried out in triplicate.

Evaluation of the tolerance of bacterial isolates to AgNPs

The MICs of AgNP_1, AgNP_2, and $\mathrm{AgNO}_{3}$ against polymyxin-resistant Escherichia coli, aminoglycoside-resistant Acinetobacter spp., Klebsiella pneumoniae ATCC 700603, Pseudomonas aeruginosa ATCC 27853, Escherichia coli ATCC 25922, and MRSA ATCC 33591 were determined using the microdilution method, according to CLSI (Clinical and Laboratory Standards Institute 2019). Subsequently, the contents of the first three wells of subinhibitory concentrations with surviving bacteria were removed from the plate and mixed. The mixture was applied in the blood agar medium in Petri dishes and incubated at $35 \pm 2{ }^{\circ} \mathrm{C}$ for $24 \mathrm{~h}$. The bacteria were then adjusted at 0.5 on the McFarland scale, diluted, and deposited in the microdilution plate wells. The final concentration was 2-5 $10^{5} \mathrm{UFC} / \mathrm{mL}$; they have then exposed again to AgNP_1, AgNP_2, or $\mathrm{AgNO}_{3}$ for the new determination of MIC, to verify, at each stage, if there was the induction of tolerance to the isolates. The methodology described refers to one step in the process. For this tolerance study, the bacteria were repeatedly exposed to $\mathrm{AgNP} \_1, \mathrm{AgNP}_{-} 2$, or $\mathrm{AgNO}_{3}$, subjecting them to 20 steps of successive cultures in microdilution plates and MIC determination. After the twentieth exposure, it was evaluated whether there was a change in MICs during consecutive exposures of bacteria to AgNPs. The whole experiment was 
carried out in triplicate, and the bacteria were considered tolerant to AgNPs when the MIC value increased at least four times (Elbehiry et al. 2019; Panáček et al. 2018).

Antibiofilm activity assessment of AgNPs

\section{Congo Red Agar method}

The qualitative determination of slime or EPS matrix production by bacterial isolates was performed according to the Congo Red Agar method (Freeman et al. 1989; Türkyilmaz and Kaynarca 2010). In this study, the polymyxin-resistant Escherichia coli clinical isolate, Klebsiella pneumoniae carbapenemase clinical isolate, Pseudomonas aeruginosa ATCC 27853, Klebsiella pneumoniae ATCC 700603, MSSA ATCC 29213, and MRSA ATCC 33591 were used.

Initially, the bacteria were adjusted to 0.5 of the McFarland scale $\left(10^{8} \mathrm{CFU} / \mathrm{mL}\right)$ in BHIB and incubated at $35 \pm 2{ }^{\circ} \mathrm{C}$ for $24 \mathrm{~h}$. Subsequently, the bacteria were seeded on plates containing Congo Red Agar and allow slime or EPS matrix production at $35 \pm 2{ }^{\circ} \mathrm{C}$ for $48 \mathrm{~h}$. After this period, the colonies that presented blackish coloration with dry or rough consistency were considered bacteria that grew on biofilms. Red colonies with mucosal consistency were considered as bacteria that did not grow on biofilms.

To evaluate the effect of AgNPs on the production of slime or EPS matrix in Congo Red Agar, the AgNPs were incorporated into the culture medium, and subsequent, the bacteria were seeded. The plates were incubated at $35 \pm 2{ }^{\circ} \mathrm{C}$ for $48 \mathrm{~h}$. After incubation, it was verified whether bacteria still produced slime or EPS matrix after exposure to AgNPs incorporated into the culture medium.

It is worth mentioning that this study is one of the few types of research incorporating silver nanoparticles-chitosan composites in Congo Red Agar to verify the inhibition of the bacteria that grow on biofilms.

\section{Violet Crystal method}

The polymyxin-resistant Escherichia coli clinical isolate, Klebsiella pneumoniae carbapenemase clinical isolate, Pseudomonas aeruginosa ATCC 27853, Klebsiella pneumoniae ATCC 700603, MSSA ATCC
29213, and MRSA ATCC 33591 were reactivated in Soy Triptona broth (STB) and subjected to biofilm formation evaluation, using the violet crystal method (Adukwu et al. 2012).

At first, TSB $+1 \%$ glucose was distributed in each well of flat bottom microdilution (TTP) plates. Then, AgNP_1, AgNP_2, and $\mathrm{AgNO}_{3}$ were added to the wells through serial dilution to obtain a concentration range of 0.1 to $50 \mu \mathrm{g} / \mathrm{mL}$. Then, the bacteria concentration was adjusted to $10^{5} \mathrm{UFC} / \mathrm{mL}$ and added to the plates. Afterward, the plates were incubated at $35 \pm 2{ }^{\circ} \mathrm{C}$ for $24 \mathrm{~h}$. Post incubation, the wells' contents were removed, the wells were washed with saline solution $0.9 \%$, and the plates were dried at room temperature. Then, the bacteria adhered to the plate were fixed with methanol 99\%. After fixation, methanol was removed, and the plates were set to dry again. Subsequently, the bacteria adhered to the plates were stained with violet crystal $0.5 \%$. The excess dye was removed, and the wells were rewashed with autoclaved distilled water. The optical density (OD) was recorded at $570 \mathrm{~nm}$ using Multiskan microplate photometer FC (Costa Lima et al. 2017). The minimum biofilm inhibitory concentration (MBIC) was the lowest concentration that inhibited $90 \%$ of the biofilm formation (Adukwu et al. 2012). The experiments were carried out in triplicate.

\section{Results and discussion}

AgNPs characterization

The two-step procedure employed in this work allows for the obtention of small spherical AgNPs initially and their subsequent use as seeds to generate bigger particles with different morphologies, as described by Stamplecoskie and Scaiano (2011). These authors, however, used ascorbic acid as a reducing agent and sodium citrate as the stabilizer. In this study, we used $\mathrm{NaBH}_{4}$ and chitosan, respectively, similarly to the strategy reported by Bin-Ahmad et al. (2011). Since the volumes of the $\mathrm{Ag}+$ solution added were all the same in the second step, larger nanoparticles result when fewer seeds are added.

The normalized UV-Vis absorption spectra of the AgNP colloids are presented in Fig. 1, and representative TEM images of the nanoparticles are shown in Fig. 2. The absorption spectrum of the AgNP_1 


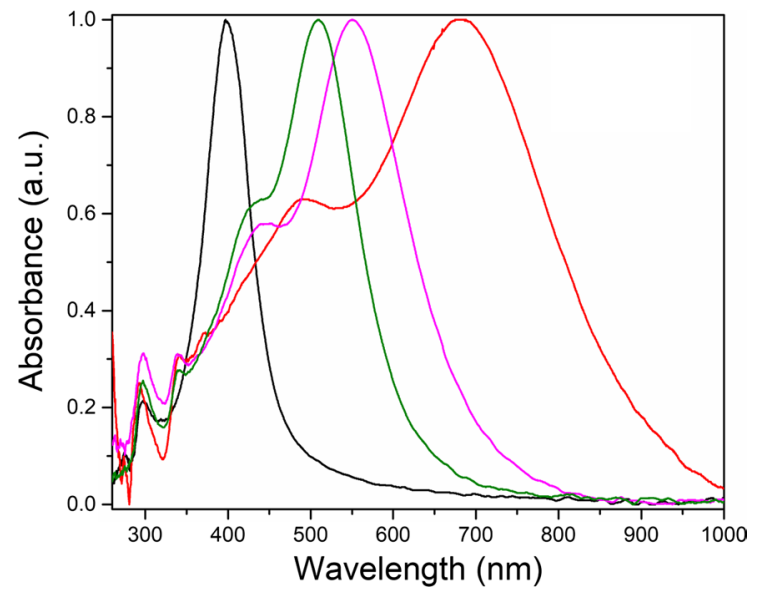

Fig. 1 UV-vis absorption spectra of the AgNP colloids. (black) AgNP_1; (green) AgNP_2; (magenta) AgNP_3; (red) AgNP_4 sample, with a single band centered at $398 \mathrm{~nm}$, is typically observed when there are only spherical nanoparticles. In the spectra of AgNP_2, 3, and 4, a shoulder appears. The maximum absorption is dislocated to higher wavelengths, which indicates that asymmetric nanoparticles and/or other morphologies appear, as demonstrated by Huang and $\mathrm{Xu}$ (2010). The maximum absorption is dislocated to higher wavelengths for larger particles (Huang and Xu 2010). Sample AgNP_2 presents mainly spherical and elliptical nanoparticles (Fig. 2b) and a small number of triangles; AgNP_3 and 4 triangular nanoparticles can also be detected (Fig. 2c,d). The maximum absorption at $700 \mathrm{~nm}$ of sample AgNP_4 is consistent with the presence of larger triangles. This shift in the maximum absorbance to higher wavelengths and the appearance of new bands is consistent with the formation of particles with different sizes and morphologies, as reported by other authors (Huang and $\mathrm{Xu}$ 2010; Yang et al. 2007).
Fig. 2 Transmission electron images of the silver nanoparticles-chitosan composites. a AgNP_1; b AgNP_2; b AgNP_3; d AgNP_4

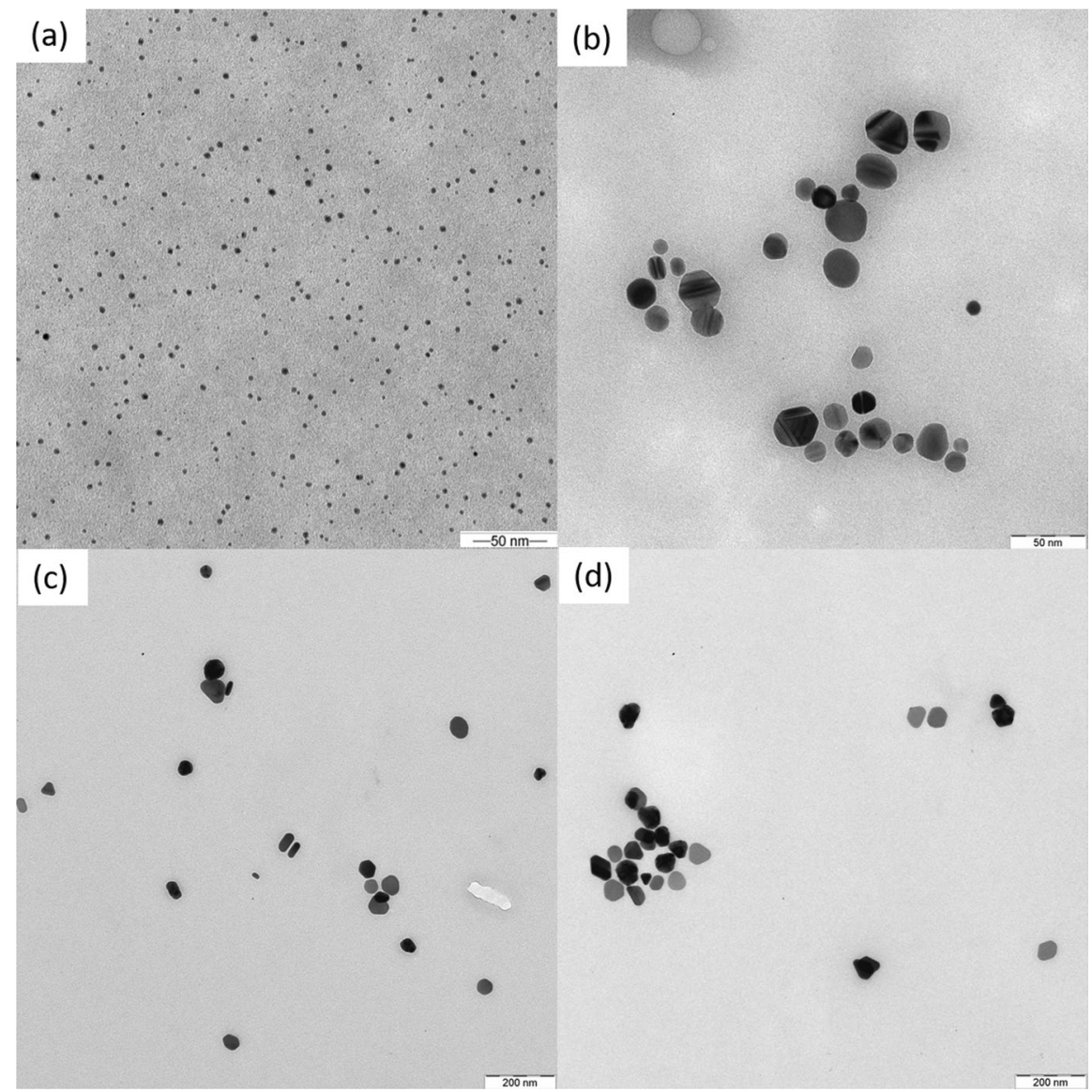




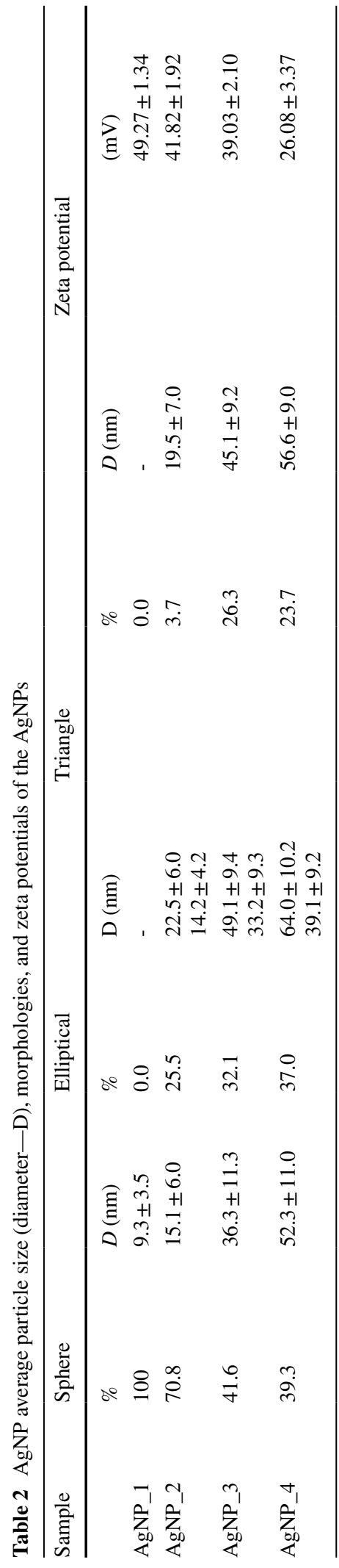

The TEM images were analyzed using software (iTEM), and at least 300 nanoparticles were measured to generate the statistics present in Table 2. Additional images of all samples are also providing as Supplementary Material. The AgNP_1 sample presents only spherical particles, as shown in Fig. 2a, with an average of $9.3 \pm 3.5 \mathrm{~nm}$. Sample AgNP_2 (Fig. 2b) also presents ellipsoidal particles and a small number of triangles $(\sim 3 \%)$. In samples AgNP_3 and AgNP_4 (Fig. 2c,d), the amount of triangular nanoparticles are above $23 \%$. The percentages change from sample to sample, and the particle dimensions increase despite the morphology from AgNP_2 to AgNP_4. The particle sizes, morphologies, and percentages are detailed in Table 2. The zeta potentials are higher than $20 \mathrm{mV}$ for all samples, which means that they present good colloidal stability.

Evaluation of the antibacterial activity of AgNPs

The MICs and MBCs values of $\mathrm{AgNO}_{3}$ and AgNPs against Gram-positive and Gram-negative bacteria are shown in Table 3. The MICs and MBCs of $\mathrm{AgNO}_{3}$ ranged from 6.3 to $25 \mu \mathrm{g} / \mathrm{mL}$ and 12.5 to $50.0 \mu \mathrm{g} / \mathrm{mL}$, respectively. These values are higher when compared with AgNPs in most of the experiments. MICs and MBCs were lower for the AgNP colloid with smaller and spherical nanoparticles.

The smaller and spherical nanoparticles (AgNP_1) presented MICs ranging from 0.8 to $3.1 \mu \mathrm{g} / \mathrm{mL}$ while the three samples with rod-, oval-, and triangle-shaped nanoparticles (AgNP_2, AgNP_3, and AgNP_4) presented values in the $3.1-25.0 \mu \mathrm{g} / \mathrm{mL}$ range.

Liao et al. (2019) recently reported silver nanoparticles' antibacterial activity and mechanism against multidrug-resistant Pseudomonas aeruginosa. The MIC values found ranged from 1.406 to $5.625 \mu \mathrm{g} / \mathrm{mL}$ and MBC from 2.813 to $5.625 \mu \mathrm{g} / \mathrm{mL}$. Shaker and Shaaban (2017) produced AgNPs from strains of Acinetobacter baumannii and evaluated the antibacterial activity of these AgNPs against Gram-negative pathogenic bacteria, obtaining MICs ranging from 1.56 to $3.125 \mu \mathrm{g} / \mathrm{mL}$. In the study performed by Erjaee, Rajaian, and Nazifi (2017), AgNPs synthesized using Chamaemelum nobile extract presented MIC ranging from 15.6 to $31.2 \mu \mathrm{g} / \mathrm{mL}$ and MBC between 15.6 and $62.5 \mu \mathrm{g} / \mathrm{mL}$ against Gram-positive pathogenic bacteria, including Staphylococcus aureus. 
Table 3 Antibacterial activity of AgNPs against pathogenic bacteria

\begin{tabular}{|c|c|c|c|c|c|c|}
\hline \multirow[t]{2}{*}{ Bacteria } & \multicolumn{3}{|c|}{$\mathrm{MIC}(\mu \mathrm{g} / \mathrm{mL})$} & \multicolumn{3}{|c|}{$\mathrm{MBC}(\mu \mathrm{g} / \mathrm{mL})$} \\
\hline & $\mathrm{AgNO}_{3}$ & AgNP_1 & AgNPs_2,3,4 & $\mathrm{AgNO}_{3}$ & AgNP_1 & AgNPs_2,3,4 \\
\hline \multicolumn{7}{|l|}{ Gram-positive } \\
\hline MSSA ATCC 29213 & 6.3 & 0.8 & $3.1-6.3$ & 50.0 & 3.1 & $3.1-6.3$ \\
\hline MRSA ATCC 33591 & 12.5 & 1.6 & $3.1-6.3$ & 50.0 & 3.1 & $3.1-6.3$ \\
\hline VRSA & 25.0 & 3.1 & 12.5 & 25.0 & 6.3 & $12.5-25.0$ \\
\hline \multicolumn{7}{|l|}{ Gram-negative } \\
\hline $\begin{array}{l}\text { Pseudomonas aeruginosa } \\
\text { ATCC } 27853\end{array}$ & 12.5 & 3.1 & $3.1-6.3$ & 25.0 & 12.5 & 25.0 \\
\hline $\begin{array}{l}\text { Klebsiella pneumoniae } \\
\text { ATCC } 700603\end{array}$ & 6.3 & 3.1 & 12.5 & 25.0 & 6.3 & 25.0 \\
\hline $\begin{array}{l}\text { Escherichia coli } \\
\text { ATCC } 25922\end{array}$ & 12.5 & 1.6 & 12.5 & 25.0 & 6.3 & $12.5-25$ \\
\hline ESBL & 6.3 & 3.1 & 6.3 & 25.0 & 6.3 & 6.3 \\
\hline Aminoglycoside-resistant Acinetobacter spp. & 12.5 & 1.6 & 3.1 & 12.5 & 6.3 & 6.3 \\
\hline Polymyxin-resistant Escherichia coli & 12.5 & 1.6 & $6.3-25.0$ & 12.5 & 3.1 & $12.5-25.0$ \\
\hline KPC & 6.3 & 3.1 & 12.5 & 25.0 & 12.5 & $12.5-25.0$ \\
\hline
\end{tabular}

$\mathrm{AgNO}_{3}$, silver nitrate aqueous solution; $\mathrm{AgNP}$, silver nanoparticles-chitosan composites; ATCC, American Type Culture Collection; MSSA, methicillin-sensitive Staphylococcus aureus; MRSA, methicillin-resistant Staphylococcus aureus; VRSA, vancomycin-resistant Staphylococcus aureus; ESBL, extended-spectrum beta-lactamase (ESBL)-producing enterobacteria; KPC, Klebsiella pneumoniae arbapenemase; $M I C$, minimum inhibitory concentration; $M B C$, minimum bactericidal concentration

Overall, the size, shape, surface charge, and structure of the nucleus are some important factors that determine the biological effects of nanoparticles, such as cell uptake, cell activation, and intercellular distribution. Regarding the size of the nanoparticles, the smallest particles have a higher surface contact area. Consequently, potentially higher amounts of $\mathrm{Ag}^{+}$ions will be released, in addition to being capable of faster dissolution in the medium (Elbehiry et al. 2019; Le Ouay and Stellacci 2015b; Helmlinger et al. 2016).

Studies conducted by Makwana et al. (2015) and Sotiriou and Pratsinis (2011) have shown that smaller silver particles are more effective. These particles release silver ions more quickly, leading to more significant toxicity due to a higher effective concentration of silver ions. Also, Sotiriou and Pratsinis (2011) found that silver nanoparticles' antibacterial effect decreased with increasing particle size, as observed in the present study (Helmlinger et al. 2016; Sotiriou and Pratsinis 2011).

Furthermore, AgNPs can physically interact with the cell surface of various bacteria and can damage cell membranes, leading to structural changes that can induce bacterial death. This effect is highly influenced by the nanoparticles' size, shape, and concentration (Le Ouay and Stellacci 2015b; Franci et al. 2015).

Some reports also indicated that the nanoparticle shape plays an essential role in antibacterial activity, especially isotropic geometries, such as spherical particles. These spherical nanoparticles demonstrated high antibacterial effectiveness, possibly because of the large surface-to-volume ratio of spherical shapes, which provided the maximum reactivity to obtain the highest antibacterial activity. Others, however, cite that nanoprisms and nanorods are more active than nanospheres due to a higher exposure of their facets, which contributed to an easier dissolution of facets of silver, leading to a faster $\mathrm{Ag}^{+}$release and thus a higher activity for nanoparticles that exhibit more of these facets (Le Ouay and Stellacci 2015b; Raza et al. 2016).

Evaluation of the tolerance of bacterial isolates to AgNPs

All bacteria used in this study did not exhibit an increase in MIC in the tolerance experiments, which would indicate tolerance when exposed to $\mathrm{AgNO}_{3}$, 
Table 4 Tolerance study of the bacteria to $\mathrm{AgNO}_{3}$ and $\mathrm{AgNPs}$. MIC $(\mu \mathrm{g} / \mathrm{mL})$ values before passage and after the $20^{\text {th }}$ passage

\begin{tabular}{|c|c|c|c|c|c|c|}
\hline \multirow[t]{2}{*}{ Bacteria } & \multicolumn{2}{|l|}{$\mathrm{AgNO}_{3}$} & \multicolumn{2}{|l|}{ AgNP_1 } & \multicolumn{2}{|l|}{ AgNP_2 } \\
\hline & Before passage & At 20th passage & Before passage & At 20th passage & Before passage & at 20th passage \\
\hline MRSA* & 12.5 & 25.0 & 3.1 & 3.1 & 12.5 & 25.0 \\
\hline P. aeruginosa ATCC 27853 & 12.5 & 12.5 & 3.1 & 6.3 & 12.5 & 12.5 \\
\hline $\begin{array}{l}\text { K. pneumoniae ATCC } \\
700603\end{array}$ & 12.5 & 12.5 & 6.3 & 12.5 & 12.5 & 12.5 \\
\hline $\begin{array}{l}\text { Polymyxin-resistant } \\
\text { Escherichia coli }\end{array}$ & 12.5 & 25.0 & 3.1 & 3.1 & 12.5 & 12.5 \\
\hline $\begin{array}{l}\text { Aminoglycoside-resist- } \\
\text { ant Acinetobacter spp. }\end{array}$ & 12.5 & 12.5 & 3.1 & 3.1 & 3.1 & 6.3 \\
\hline KPC & 12.5 & 12.5 & 3.1 & 6.3 & 12.5 & 12.5 \\
\hline
\end{tabular}

$\mathrm{AgNO}_{3}$, silver solution; $\mathrm{AgNP}$, silver nanoparticles-chitosan composites; KPC, Klebsiella pneumoniae carbapenemase; MRSA, methicillin-resistant Staphylococcus aureus; ATCC, American Type Culture Collection. ${ }^{*}$ The MIC for MRSA was $12.5 \mu \mathrm{g} / \mathrm{mL}$ after the $10^{\text {th }}$ passage

AgNP_1, and AgNP_2 for the 20 successive steps (Table 4).

Elbehiry et al. (2019) also did not observe tolerance induction in most isolates of $S$. aureus after exposure to AgNPs. From the total of 20 isolates of $S$. aureus used in that study, only 4 indicated tolerance for AgNP of $10 \mathrm{~nm}$ and 10 strains for AgNP of $20 \mathrm{~nm}$. For isolates with no indication of tolerance, the NPs' MICs remained the same after 10 passages or were lower than those initially observed. With the $10 \mathrm{~nm}$ AgNP, the S2 isolate, for example, had an initial MIC of $12.5 \mu \mathrm{g} / \mathrm{mL}$, and after 10 steps, the value was $6.25 \mu \mathrm{g} / \mathrm{mL}$. For the $\mathrm{S} 3$ isolate exposed to $20 \mathrm{~nm}$ AgNP, the initial MIC of $12.5 \mu \mathrm{g} / \mathrm{mL}$ was maintained after 10 steps.

On the other hand, there are reports in the literature on bacterial tolerance to $\mathrm{Ag}^{+}$compounds (Mijnendonckx et al. 2013). However, there are no conclusive reports on the induction of bacterial resistance by silver nanoparticles to date. Some studies have suggested that bacteria developed resistance to a sublethal dose of AgNPs, below the $\mathrm{IC}_{50}$, after successive selections of surviving cells (Kaweeteerawat et al. 2017). Panáček et al. (2018) observed that $E$. coli CCM 3954 was shown to be tolerant to AgNP after 6 successive exposures with a change in MIC from 3.38 to $13.5 \mu \mathrm{g} / \mathrm{mL}$, and in the eighth step, the MIC was already $>54 \mu \mathrm{g} / \mathrm{mL}$. Similarly, P. aeruginosa CCM 3955 and E. coli 013 became resistant to AgNPs after 11 and 13 steps, respectively. All the bacteria used in the study conducted by Panáček et al.
(2018) remained resistant to AgNPs until the end of the study, which corresponded to 20 steps.

Unlike the findings described above, the AgNPs investigated in the present study did not induce tolerance in any tested bacteria, even though the bacteria used in this study exhibit a resistance profile to drugs used in the clinic therapy.

Evaluation of antibiofilm activity

Klebsiella pneumoniae carbapenemase clinical isolate, Pseudomonas aeruginosa ATCC 27853, Klebsiella pneumoniae ATCC 700603, MSSA ATCC 29213, and MRSA ATCC 33591, in the Congo Red Agar method, produced blackish coloration with dry or rough consistency, distinctive aspects of bacteria that grow on biofilms (Fig. 3A). After exposure to AgNP_1, the slime or EPS matrix production was inhibited, revealing red colonies with mucosal texture (Fig. 3B).

The MBIC values were the same for $\mathrm{AgNO}_{3}$ and AgNP_2 against all the bacteria of this study $(\mathrm{MBIC}=50 \mu \mathrm{g} / \mathrm{mL})$. Regarding AgNP_1, the results were more promising, especially against Gram-positive bacteria $(\mathrm{MBIC}=12.5 \mu \mathrm{g} / \mathrm{mL})$. For Gram-negative bacteria, the MBIC of AgNP_1 was $25 \mu \mathrm{g} / \mathrm{mL}$ (Table 5).

Again, the smaller sized AgNPs (AgNP_1) had a more significant antibiofilm effect. Ikuma, Decho, and Lau (2015) suggest that the size of the nanoparticles is essential in the interaction with the biofilm, as it has been reported that the size of AgNPs is important 
Fig. 3 Production of slime or exopolysaccharide (EPS) matrix by Klebsiella pneumoniae carbapenemase clinical isolate characterized by blackish coloration, with dry or rough consistency, before being exposed to AgNP_1 (A) and absence of slime or EPS matrix after exposure to AgNP_1 revealing red colonies with mucosal texture without blackish coloration (B)
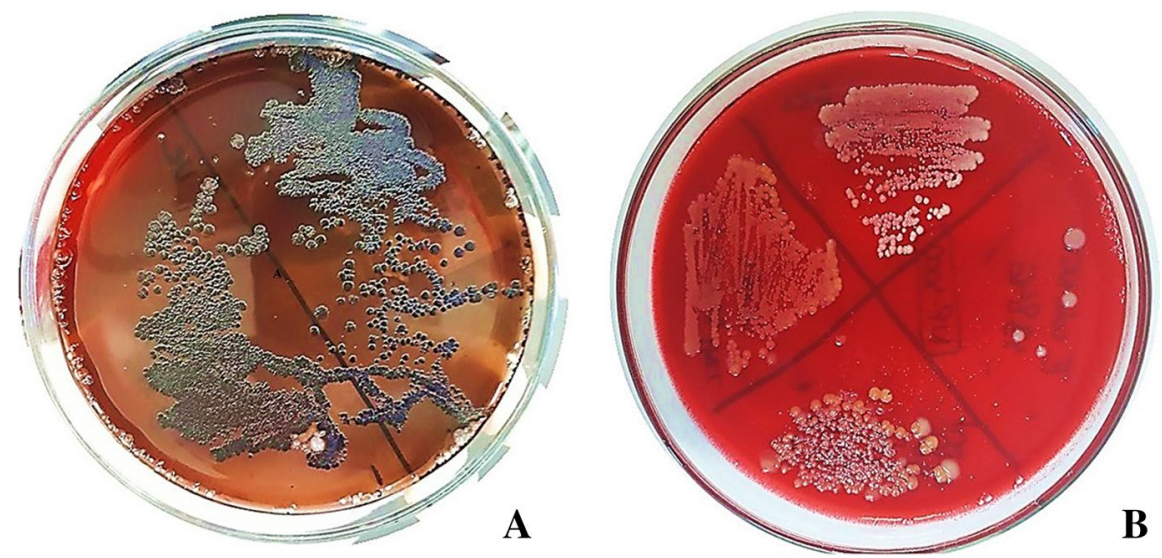

Table 5 Antibiofilm activity of the AgNPs

\begin{tabular}{lllll}
\hline Bacteria group & Bacteria & MBIC $(\mu \mathrm{g} / \mathrm{mL})$ & \\
\cline { 3 - 5 } & & $\mathrm{AgNO}_{3}$ & AgNP_1 & AgNP_2 \\
\hline Gram-positive & MSSA ATCC 29213 & 50 & 12.5 & 50 \\
& MRSA ATCC 33591 & 50 & 12.5 & 50 \\
Gram-negative & Pseudomonas aeruginosa@ATCC 27853 & 50 & 25 & 50 \\
& Klebsiella pneumoniae@ ATCC 700603 & 50 & 25 & 50 \\
& Polymyxin-resistant Escherichia coli & 50 & 25 & 50 \\
& KPC & 50 & 50 \\
\hline
\end{tabular}

$M B I C$, minimum biofilm inhibitory concentration; $\mathrm{AgNO}_{3}$, silver solution; $\mathrm{AgNP}$, silver nanoparticles-chitosan composites; $A T C C$, American Type Culture Collection; MSSA, methicillin-sensitive Staphylococcus aureus; MRSA, methicillin-resistant Staphylococcus aureus; KPC, Klebsiella pneumoniae carbapenemase

in modulating their transport in biofilms, with their diffusion coefficients decreasing with increasing size of the nanoparticle.

Other studies in the literature have also highlighted the antibiofilm potential of silver nanoparticles. Lotha et al. (2018) developed silver nanoparticles synthesized from Capsicum annuum L. extract and obtained more promising $\mathrm{MBIC}_{50}$ values with Gram-positive bacteria, ranging from 4 to $16 \mu \mathrm{g} / \mathrm{mL}$. As for Gramnegative bacteria, in the study conducted by Lotha et al. (2018), the $\mathrm{MBIC}_{50}$ varied between 16 and $32 \mu \mathrm{g} / \mathrm{mL}$. In the studies of Siddiqui et al. (2020), who synthesized AgNPs by chemical reduction, there was no significant difference between MBIC values obtained compared to their bacterial groups used (MBIC ranging from 75 to $150 \mu \mathrm{g} / \mathrm{mL}$ ). The study included Gram-positive bacteria ( $S$. aureus and $S$. epidermidis) and Gram-negative bacteria ( $P$. aeruginosa and Klebsiella pneumoniae). Besides, other studies point to an increase in biofilm inhibition with the increasing concentration of AgNPs, as the authors found inhibition of approximately $92 \%$ and $62 \%$ of $S$. aureus biofilm after exposure to AgNP at concentrations of $100 \mu \mathrm{g} / \mathrm{mL}$ and $75 \mu \mathrm{g} / \mathrm{mL}$, respectively (Vanaraj et al. 2017).

\section{Conclusions}

Silver nanoparticles-chitosan composites synthesized in this work exhibit promising antibacterial and antibiofilm therapeutic potential. The samples with spherical AgNPs and the smallest size presented the best results for both Gram-positive bacteria Gram-negative with and without resistance profiles. Also, silver nanoparticles-chitosan composites did not induce tolerance in the bacteria. Thus, the AgNPs developed in this study have the potential to be applied as 
nanotechnological therapeutic products in combating multidrug-resistant bacterial infections and bacteria growth on biofilms without inducing tolerance in bacteria.

Acknowledgements The authors are grateful for Dr. Douglas Soares da Silva from IQ-UNICAMP for Transmission Electron Microscopy images and Instituto Nacional de Ciência e Tecnologia em Materiais Complexos Funcionais INOMAT/ CNPq.

Funding This work was supported by the Foundation of Support for Science and Technology of the State of Pernambuco (FACEPE) [APQ-0814-4.03/17].

\section{Declarations}

Conflict of interest The authors declare no competing interest.

\section{References}

Adukwu EC, Allen SCH, Phillips CA (2012) The anti-biofilm activity of lemongrass (Cymbopogon flexuosus) and grapefruit (Citrus paradisi) essential oils against five strains of Staphylococcus aureus. J Appl Microbiol 113:1217-1227. https://doi.org/10.1111/j.1365-2672. 2012.05418.x

Bin-Ahmad M, Lim JJ, Shameli K et al (2011) Synthesis of silver nanoparticles in chitosan, gelatin and chitosan/gelatin bionanocomposites by a chemical reducing agent and their characterization. Molecules 16:7237-7248. https://doi. org/10.3390/molecules 16097237

Brazil (1997) Law No. 9.431, January 6, 1997. Provides for the mandatory maintenance of a hospital infection control program by hospitals in the country. http://www.planalto. gov.br/ccivil_03/Leis/L9431.htm. Accessed 21 May 2020

CDC (2019) Biggest threats and data. https://www.cdc.gov/ drugresistance/biggest-threats.html

Chaloupka K, Malam Y, Seifalian AM (2010) Nanosilver as a new generation of nanoproduct in biomedical applications. Trends Biotech 28:580-588. https://doi.org/10. 1016/j.tibtech.2010.07.006

Clinical and Laboratory Standards Institute (2019) M100-S27. Performance standards for antimicrobial susceptibility testing: informational supplement. Clinical and Laboratory Standards Institute (CLSI), Wayne, PA.

Da Costa Lima JL, Alves LR, Da Paz JNP et al (2017) Analysis of biofilm production by clinical isolates of Pseudomonas aeruginosa from patients with ventilator-associated pneumonia. Rev Bras Ter Intensiva 29:310-316. https://doi. org/10.5935/0103-507X.20170039

Dos Santos VE, Filho AV, Ribeiro Targino AG et al (2014) A new "silver-Bullet" to treat caries in children - nano silver fluoride: a randomised clinical trial. J Dent 42:945-951. https://doi.org/10.1016/j.jdent.2014.05.017
Elbehiry A, Al-Dubaib M, Marzouk E, Moussa I (2019) Antibacterial effects and resistance induction of silver and gold nanoparticles against Staphylococcus aureusinduced mastitis and the potential toxicity in rats. MicrobiologyOpen 8:1-16. https://doi.org/10.1002/ mbo3.698

Erjaee H, Rajaian H, Nazifi S (2017) Synthesis and characterization of novel silver nanoparticles using Chamaemelum nobile extract for antibacterial application. Adv Nat Sci Nanosci Nanotechnol 8:25004. https://doi.org/ 10.1088/2043-6254/aa690b

Flemming HC, Wingender J, Szewzyk U et al (2016) Biofilms: an emergent form of bacterial life. Nat Rev Microbiol 14:563-575. https://doi.org/10.1038/nrmicro. 2016.94

Franci G, Falanga A, Galdiero S et al (2015) Silver nanoparticles as potential antibacterial agents. Molecules 20:88568874. https://doi.org/10.3390/molecules20058856

Freeman DJ, Falkiner FR, Keane CT (1989) New method for detecting slime production by coagulase negative staphylococci. J Clin Pathol 42:872-874. https://doi.org/10. 1136/jcp.42.8.872

Freire PLL, Stamford TCM, Albuquerque AJR et al (2015) Action of silver nanoparticles towards biological systems: cytotoxicity evaluation using hen's egg test and inhibition of Streptococcus mutans biofilm formation. Int J Antimicrob Agents 45:183-187. https://doi.org/10.1016/j.ijant imicag.2014.09.007

Freire PLL, Albuquerque AJR, Farias IAP, Silva TG et al (2016) Antimicrobial and cytotoxicity evaluation of colloidal chitosan - silvernanoparticles - fluoride nanocomposites. Intern J Biol Macromol 93:896-903. https://doi. org/10.1016/j.ijbiomac.2016.09.052

Goy RC, Britto DD, Assis OB (2009) A review of the antimicrobial activity of chitosan. Polímeros 19:241-247

Gurunathan S, Han JW, Kwon DN, Kim JH (2014) Enhanced antibacterial and anti-biofilm activities of silver nanoparticles against Gram-negative and Gram-positive bacteria. Nanoscale Res Lett 9:1-17. https://doi.org/10.1186/ 1556-276X-9-373

Hauser AR, Mecsas J, Moir DT (2016) Beyond antibiotics: new therapeutic approaches for bacterial infections. Clin Infect Dis 63:89-95. https://doi.org/10.1093/cid/ciw200

Helmlinger J, Sengstock C, Groß-Heitfeld C et al (2016) Silver nanoparticles with different size and shape: equal cytotoxicity, but different antibacterial effects. RSC Adv 6:18490-18501. https://doi.org/10.1039/c5ra27836h

Huang T, Xu X-HN (2010) Synthesis and characterization of tunable rainbow colored colloidal silvernanoparticles using single-nanoparticle plasmonic microscopy and spectroscopy. J Mater Chem 20:9867-9876. https://doi. org/10.1039/C0JM01990A

Huang H, Yang X (2004) Synthesis of polysaccharide-stabilized gold and silver nanoparticles: a green method. Carbohydr Res 339:2627-2631. https://doi.org/10.1016/j. carres.2004.08.005

Ikuma K, Decho AW, Lau BLT (2015) When nanoparticles meet biofilms - Interactions guiding the environmental fate and accumulation of nanoparticles. Front Microbiol 6:1-6. https://doi.org/10.3389/fmicb.2015.00591 
Jamal M, Ahmad W, Andleeb S et al (2018) Bacterial biofilm and associated infections. J Chinese Med Assoc 81:7-11. https://doi.org/10.1016/j.jcma.2017.07.012

Jenkins DR (2017) Nosocomial infections and infection control. Med (United Kingdom) 45:629-633. https://doi.org/ 10.1016/j.mpmed.2017.07.005

Kasaai MR, Arul J, Charlet G (2000) Intrinsic viscosity-molecular weight relationship for chitosan. J Polymer Science B 38:2591-2598. https://doi.org/10.1002/1099-0488(20001 001)38:19\%3c2591::AID-POLB110\%3e3.0.CO;2-6

Kaweeteerawat C, Na Ubol P, Sangmuang S et al (2017) Mechanisms of antibiotic resistance in bacteria mediated by silver nanoparticles. J Toxicol Environ Heal - Part A Curr Issues 80:1276-1289. https://doi.org/10.1080/15287394. 2017.1376727

Khameneh B, Diab R, Ghazvini K, Fazly Bazzaz BS (2016) Breakthroughs in bacterial resistance mechanisms and the potential ways to combat them. Microb Pathog 95:32-42. https://doi.org/10.1016/j.micpath.2016.02.009

Le Ouay B, Stellacci F (2015a) Antibacterial activity of silvernanoparticles: a surface science insight. Nano Today 10:339-354. https://doi.org/10.1016/j.nantod.2015.04.002

Le Ouay B, Stellacci F (2015b) Antibacterial activity of silver nanoparticles: a surface science insight. Nano Today 10:339-354. https://doi.org/10.1016/j.nantod.2015.04.002

Liao S, Zhang Y, Pan X et al (2019) Antibacterial activity and mechanism of silver nanoparticles against multidrugresistant Pseudomonas aeruginosa. Int J Nanomedicine 14:1469-1487. https://doi.org/10.2147/IJN.S191340

Lotha R, Shamprasad BR, Sundaramoorthy NS et al (2018) Zero valent silver nanoparticles capped with capsaicinoids containing Capsicum annuum extract, exert potent anti-biofilm effect on food borne pathogen Staphylococcus aureus and curtail planktonic growth on a zebrafish infection model. Microb Pathog 124:291-300. https://doi.org/ 10.1016/j.micpath.2018.08.053

Makwana BA, Vyas DJ, Bhatt KD et al (2015) Highly stable antibacterial silver nanoparticles as selective fluorescent sensor for Fe3+ ions. Spectrochim Acta - Part A Mol Biomol Spectrosc 134:73-80. https://doi.org/10.1016/j.saa. 2014.05.044

Marambio-Jones C, Hoek EMV (2010) A review of the antibacterial effects of silver nanomaterials and potential implications for human health and the environment. $\mathbf{J}$ Nanopart Res 12:1531-1551. https://doi.org/10.1007/ s11051-010-9900-y

Marston HD, Dixon DM, Knisely JM et al (2016) Antimicrobial resistance. JAMA - J Am Med Assoc 316:1193-1204. https://doi.org/10.1001/jama.2016.11764

Mijnendonckx K, Leys N, Mahillon J et al (2013) Antimicrobial silver: uses, toxicity and potential for resistance. Biometals 26:609-621. https://doi.org/10.1007/ s10534-013-9645-Z

Moore GK, Roberts GAF (1980) Determination the degree of $\mathrm{n}$-acetylation of chitosan. Int $\mathrm{J}$ of Biolog Macrom 2:115-116

Morris DE, Cleary DW, Clarke SC (2017) Secondary bacterial infections associated with influenza pandemics. Front Microbiol 8:104. https://doi.org/10.3389/fmicb.2017. 01041
Natan M, Banin E (2017) From nano to micro: using nanotechnology to combat microorganisms and their multidrug resistance. FEMS Microbiol Rev 41:302-322. https://doi. org/10.1093/femsre/fux003

Noronha VT, Paula AJ, Durán G et al (2017) Silver nanoparticles in dentistry. Dent Mater 33:1110-1126. https://doi. org/10.1016/j.dental.2017.07.002

Pal S, Tak YK, Song JM (2007) Does the antibacterial activity of silver nanoparticles depend on the shape of thenanoparticle? A study of the Gram-negative bacterium Escherichia coli. Appl Environ Microbiol 73:1712-1720. https:// doi.org/10.1128/AEM.02218-06

Panáček A, Kvítek L, Smékalová M et al (2018) Bacterial resistance to silver nanoparticles and how to overcome it. Nat Nanotechnol 13:65-71. https://doi.org/10.1038/ s41565-017-0013-y

Raza MA, Kanwal Z, Rauf A et al (2016) Size- and shapedependent antibacterial studies of silver nanoparticles synthesized by wet chemical routes. Nanomaterials 6:74. https://doi.org/10.3390/nano6040074

Shaker MA, Shaaban MI (2017) Synthesis of silver nanoparticles with antimicrobial and anti-adherence activities against multidrug-resistant isolates from Acinetobacter baumannii. J Taibah Univ Med Sci 12:291-297. https:// doi.org/10.1016/j.jtumed.2017.02.008

Siddiqui A, Anwar H, Ahmed SW et al (2020) Synthesis and sensitive detection of doxycycline with sodium bis 2-ethylhexylsulfosuccinate based silver nanoparticle. Spectrochim Acta - Part A Mol Biomol Spectrosc 225:117489. https://doi.org/10.1016/j.saa.2019.117489

Sotiriou GA, Pratsinis SE (2011) Engineering nanosilver as an antibacterial, biosensor and bioimaging material. Curr Opin Chem Eng 1:3-10. https://doi.org/10.1016/j.coche. 2011.07.001

Ssekatawa K, Byarugaba DK, Kato CD et al (2020) Nanotechnological solutions for controlling transmission and emergence of antimicrobial-resistant bacteria, future prospects, and challenges: a systematic review. J Nanopart Res 22:130. https://doi.org/10.1007/s11051-020-04817-7

Stamplecoskie KG, Scaiano JC (2011) Optimal size of silver nanoparticles for surface-enhanced raman spectroscopy. J Phys Chem C 115:1403-1409. https://doi.org/10.1021/ jp106666t

Targino AGR, Flores MAP, Dos Santos VE et al (2014) An innovative approach to treating dental decay in children. A new anti-caries agent. J Mater Sci Mater Med 25:20412047. https://doi.org/10.1007/s10856-014-5221-5

Türkyilmaz S, Kaynarca S (2010) The slime production by yeasts isolated from subclinical mastitic cows. Acta Vet Brno 79:581-586. https://doi.org/10.2754/avb2010790 40581

Vanaraj S, Keerthana BB, Preethi K (2017) Biosynthesis, characterization of silver nanoparticles using quercetin from Clitoria ternatea $\mathrm{L}$ to enhance toxicity against bacterial biofilm. J Inorg Organomet Polym Mater 27:1412-1422. https://doi.org/10.1007/s10904-017-0595-8

Venkatesan N, Perumal G, Doble M (2015) Bacterial resistance in biofilm-associated bacteria. Future Microbiol 10:17431750. https://doi.org/10.2217/fmb.15.69 
Wang L, Hu C, Shao L (2017) The-antimicrobial-activityof-nanoparticles-present-situati. Int $\mathrm{J}$ Nanomedicine 12:1227-1249. https://doi.org/10.2147/IJN.S121956

WHO (2002) Prevention of hospital-acquired infections. https://www.who.int/csr/resources/publications/WHO_ CDS_CSR_EPH_2002_12/en/. Accessed 21 May 2020

WHO (2015) Global action plan on antimicrobial resistance. Microbe Mag 10:354-355. https://doi.org/10.1128/micro be. 10.354 .1

WHO (2019) Ten threats to global health in 2019. https://www. who.int/news-room/feature-stories/ten-threats-to-globalhealth-in-2019. Accessed 18 May 2020

Yang Y, Matsubara S, Xiong L et al (2007) Solvothermal synthesis of multiple shapes of silver nanoparticles and their SERS properties. J Phys Chem C 111:9095-9104. https:// doi.org/10.1021/jp068859b

Yang EJ, Jang J, Kim S, Choi IH (2012) Silver nanoparticles as a smart antimicrobial agent. J Bacteriol Virol 42:177-179. https://doi.org/10.4167/jbv.2012.42.2.177
Zhang X-F, Liu Z-G, Shen W (2016) Gurunathan S. Silver nanoparticles: synthesis, characterization, properties, applications, and therapeutic approaches. Int J Mol Sci 17:1534. https://doi.org/10.3390/ijms17091534

Zheng K, Setyawati MI, Leong DT, Xie J (2018) Antimicrobial silver nanomaterials. Coord Chem Rev 357:1-17. https:// doi.org/10.1016/j.ccr.2017.11.019

Publisher's Note Springer Nature remains neutral with regard to jurisdictional claims in published maps and institutional affiliations. 